\title{
Use of Pressured-Air for Cotton Lint Cleaning
}

\author{
Ruixiu Sui ${ }^{1}$ \\ ${ }^{1}$ USDA-ARS Sustainable Water Management Research Unit, Stoneville, Mississippi, USA \\ Correspondence: Ruixiu Sui, USDA-ARS Sustainable Water Management Research Unit, Stoneville, MS 38776 , \\ USA. Tel: 1-662-686-5382. E-mail: ruixiu.sui@usda.gov
}

Received: September 21, 2019

Accepted: November 20, 2019 Online Published: December 15, 2019

doi:10.5539/jas.v12n1p31

URL: https://doi.org/10.5539/jas.v12n1p31

\begin{abstract}
Saw-type lint cleaner (STLC) was most efficient lint cleaner in cotton ginning. However, STLC damaged fiber quality. An air-bar lint cleaner (ABLC) was developed and evaluated to preserve cotton fiber quality. The ABLC used pressurized-air to remove non-lint materials from cotton fiber. During lint cleaning process, non-lint materials attached to the fiber were blown off the fiber without the fiber making aggressive mechanical contact with a grid bar in conventional saw-type lint cleaner (STLC). It was expected using this concept that the fiber quality could be preserved by reducing the damage from mechanical impact of the fiber against the grid bar. Preliminary testing of the ABLC prototype showed that ABLC generated less lint waste and had a higher turnout rate than STLC. Use of ABLC could save $2.8 \mathrm{~kg}$ of lint in each $225 \mathrm{~kg}$ bale of cotton. The High Volume Instrument (HVI) analysis indicated the fiber properties in fiber length, uniformity, short fiber content, and color were not significantly different between ABLC and STLC. However, the Advanced Fiber Information System (AFIS) tests showed STLC had better performance than ABLC in fiber length and short fiber content while the trash and dust content with ABLC was lower than the STLC. More research was necessary to further prove the concept of ABLC and improve its performance in preserving cotton fiber quality.
\end{abstract}

Keywords: cotton, cotton fiber quality, cotton lint cleaner, pressurized-air

\section{Introduction}

The U.S. cotton industry must improve production efficiency and fiber quality to remain competitive with foreign cotton and synthetic fiber production. Textile mills are demanding higher quality cotton as spinning technology changes and processing rates increase. Improvements in cotton ginning offer significant potential for increasing production efficiency and fiber quality, benefitting the entire industry from producer to textile mill. The introduction and adoption of new technology is crucial and will likely have more impact as gin numbers continue to decline and individual gin capacity continues to increase.

Machine-harvested cotton contained a lot of foreign matters (Funk et al., 2005). In cotton ginning process, cylinder cleaners and stick machines were used to remove the large particles of the foreign matter in seed-cotton before the gin stand to separate cotton fiber and seed. After fiber-seed separation, lint cleaners were used to remove smaller particles that remain in the cotton. Saw-type lint cleaner (STLC) was most efficient lint cleaner in cotton ginning. However, STLC damaged fiber quality by increasing nep level, reducing fiber length, and increasing short fiber content (Thomasson et al., 2007; Gordon \& Bagshaw, 2007).

Since cotton fiber quality becomes more and more important in cotton industry, researchers have been working to develop new methodologies and mechanical systems reducing fiber damage and fiber loss while retaining the high efficiency of STLC (Columbus, 1985; Baker, 1987; Hughs et al., 1992; Rutherford et al., 1999). Though performance of STLC was improved using the technologies developed in the researches, the basic cleaning principles remained the same as being developed in the 1940s. Textile mills have placed greater emphasis on fiber quality, particularly related to short fiber content and neps. New principles of lint cleaning need to be investigated to better preserve fiber quality.

Sui and Byler (2012) developed a prototype of Air-bar lint cleaner (ABLC). They used commercial nozzle arrays to build an air-bar. The air-bar was mounted in the saw-type lint cleaner replacing the first grid-bar of the cleaner. In operation, the air-bar was connected to pressurizd-air source. Using pressurized airflow, the air-bar removed non-lint materials from cotton fiber while the cotton fiber batt was on a rotating saw cylinder. Thus, non-lint materials attached to the fiber were blown off the fiber without the fiber aggressively making mechanical contact 
with the grid bar. Thus, fiber quality could be preserved by reducing the damage from mechanical impact of the fiber against the grid bar in STLC. Preliminary testing of that ABLC prototype showed that ABLC had better performance in preserving fiber quality in comparison with the conventional saw-type lint cleaner. However, in building the air-bar for the ABLC, there were gaps between the nozzles, which caused the air flow across the air-bar not evenly distributed. That might affect the effectiveness of the air-bar in the cleaning process.

The objective of this project was to continue the study on the ABLC reported by Sui and Byler (2012). A new prototype of air-bar was designed, built, and implemented on a lint cleaner. Construction and evaluation of the lint cleaner with the new air-bar were reported in this article.

\section{Material and Method}

\subsection{System Design}

Based on the principle reported by Sui and Byler (2012), a new air-bar device was designed and built for an ABLC. The air-bar device basically was a nozzle array made of aluminum alloy bar, which was $419 \mathrm{~mm} \mathrm{~L} \times 60$ $\mathrm{mm} \mathrm{W} \times 25 \mathrm{~mm} \mathrm{D}$ (Figure 1a). Size of each nozzle was $1.02 \mathrm{~mm}$ in diameter. Distance between individual nozzles was $3.2 \mathrm{~mm}$. Three air intakes were used in the air-bar to connect to a pipe for inputting pressurized-air from an air compressor. A metal bracket was built at each end of the air-bar. The air-bar was mounted on a lint cleaner using the bracket which allow adjusting airflow direction of the nozzle array and the distance from the nozzle array to the saw cylinder (Figure 1b).

To make the ABLC prototype, the first grid bar of a conventional STLC (Anthony \& McCaskill, 1972) was replaced by the air-bar device (Figure 1c). The horizontal distance between the tip of air-bar nozzle array and saw teeth of the saw cylinder was set up to be $9.5 \mathrm{~mm}$. The angle of nozzle array tip toward the saw cylinder was zero degree. An air compressor (Ingersoll Rand, 170/175 Lakeview Drive, Airside Business Park, Swords, Co. Dublin, Ireland) was employed to provide pressurized-air for the air-bar in ABLC. A pressure regulator was used between the air compressor and the air-bar to keep the air pressure to the air-bar constant.

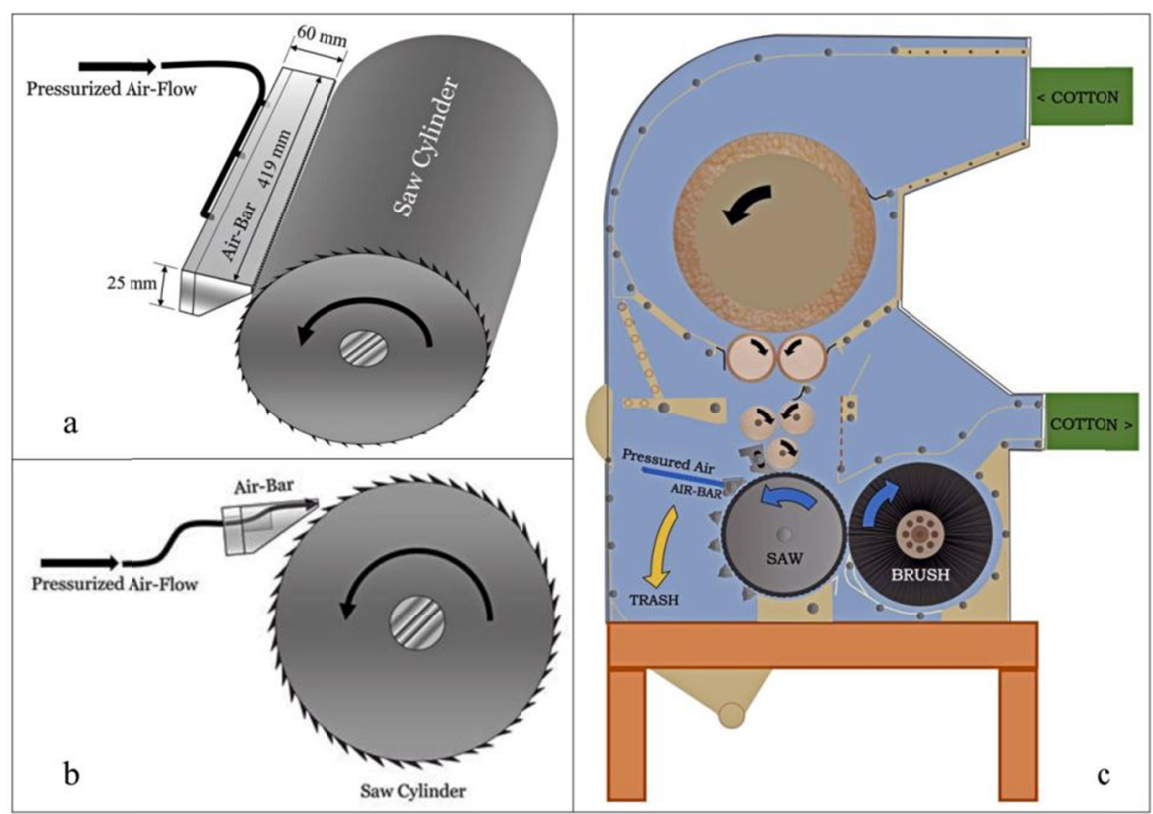

Figure 1. a) air-bar device with the saw cylinder; b) showing the air-bar and the saw cylinder (side-view). c) the air-bar was implemented in cotton lint cleaner replacing the first grid bar.

This lint cleaner was tested as the ABLC

\subsection{Test Procedure}

The ABLC prototype was tested at the USDA-ARS Cotton Ginning Research Unit (CGRU) at Stoneville, Mississippi. Performance of the ABLC was compared with a conventional STLC which was identical to the ABLC except its first grid bar. In the test, the ABLC and the STLC were arranged allowing either of them to be selected for use in the ginning process. 
The experimental design was a complete randomized design with two treatment, ABLC and STLC. Each treatment was replicated three times resulting in six runs in total, three runs in ABLC and three in STLC. Seed-cotton (Variety: FM1944GLB2) was randomly selected and bagged from a seed-cotton trailer. The bagged seed-cotton was moved to the Stoneville Micro-Gin 72 hours before running the test. In each run, three bags of seed-cotton (about $100 \mathrm{~kg}$ ) were ginned. In the ginning process, only one lint cleaner (ABLC or STLC) was used, and all ginning equipment and conditions involved, except the lint cleaner, were identical for each run. The ginning sequence included dryer 1, cylinder cleaner, stick machine, dryer 2, cylinder cleaner, extractor feeder and gin stand, and ABLC or STLC (Figure 2). Low heat was used in the first dryer. Air pressure supplied to the air-bar was $827.4 \mathrm{kPa}(120 \mathrm{psi})$.

For each run, the seed-cotton and the lint were weighed. Three seed-cotton samples and three lint samples were collected for moisture content (MC). After the lint cleaner, five lint samples were taken for Advance Fiber Information System (AFIS) analysis and five lint samples taken for High Volume Instrument (HVI) analysis. Lint waste was collected and weighed in each run as well. AFIS, HVI (Zellweger Uster, 1997), and MC analysis of the samples was conducted in the CGRU lab. Lint cleaner waste was analyzed using a Shirley Trash Separator at CGRU lab as well.

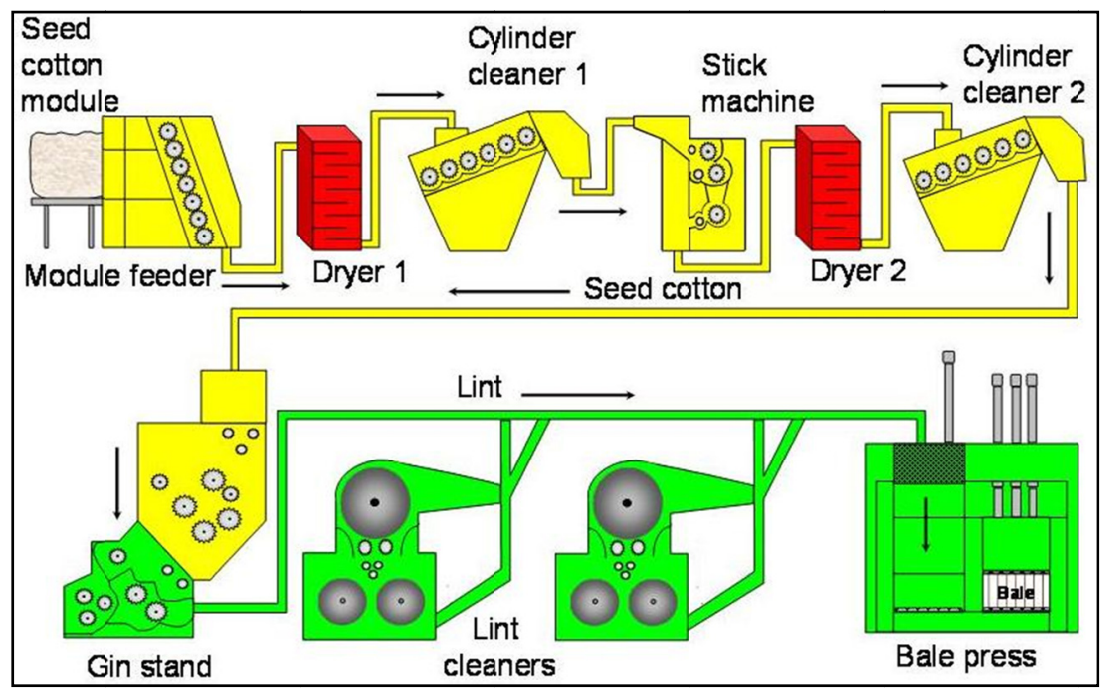

Figure 2. Ginning sequence used in testing the performance of ABLC in the Micro-Gin of CGRU

\subsection{Shirley Separation}

Three lint waste samples in amount of $75 \mathrm{~g}$ were taken from the lint waste of each run. The samples were processed using a Shirley Analyzer to separate the lint and foreign matter. Outputs after the Shirley analyzing, including cleaned lint, visible waste, visible waste in the top tray, and visible waste in the bottom tray, were weighed, respectively.

\subsection{Data Analysis}

The data from AFIS and HVI analyses of the samples were analyzed using ANOVA procedure and a Tukey's Studentized Range (HSD) Test with SAS (Cary, North Carolina, USA) to compare the effect of ABLC and STLC on fiber quality. Lint waste rate, which was the ratio of the lint waste weight to the lint weight in each run, was calculated. Lint waste rate and Shirley separation data were also analyzed using ANOVA to find the effect of the lint cleaners on lint waste.

\section{Result and Discussion}

\subsection{AFIS Analysis}

Means and standard deviation of AFIS properties of lint in ABLC and STLC treatments were given in Table 1. A one-way ANOVA test revealed that the fiber length $(\mathrm{L}(\mathrm{w}))$, short fiber content $(\mathrm{SFC}(\mathrm{w}))$, upper quarter length (UQL(w)), fiber fineness (Fineness), and maturity rate (Mat) differed significantly as a function of the lint cleaner $(\mathrm{p}<0.05)$. The other AFIS properties, including nep content, dust, trash count, and total trash were not significantly different between ABLC and STLC. The STLC slightly increased L(w) and UQL(w), and reduced 
SFC(w) by $1.5 \%$. However, the total trash and dust count with STLC was higher than ABLC. This could be due to pressurized-air effectively removing trash and dust during the lint cleaning process. In the test reported by Sui and Byler (2012), the L(w) and UQL(w) did not differ between their ABLC and STLC, but the ABLC had a lower SFC(w) than the STLC.

Table 1. Effect of the lint cleaners on the selected AFIS fiber quality

\begin{tabular}{lllllll}
\hline \multirow{2}{*}{ AFIS Fiber Property } & \multicolumn{2}{c}{ ABLC } & & \multicolumn{2}{c}{ STLC } & \multirow{2}{*}{$\operatorname{Pr}>$ F } \\
\cline { 2 - 3 } \cline { 5 - 6 } & Mean* & Std & & Mean & Std & \\
\hline Nep (cnt/g) & $214.2^{\mathrm{a}}$ & 27.2 & & $208.9^{\mathrm{a}}$ & 22.3 & 0.5747 \\
Total Trash (cnt/g) & $337.1^{\mathrm{a}}$ & 71.2 & & $370.8^{\mathrm{a}}$ & 117.9 & 0.3567 \\
Dust (cnt/g) & $273.8^{\mathrm{a}}$ & 61.6 & & $307.9^{\mathrm{a}}$ & 119.5 & 0.3377 \\
Trash (cnt/g) & $63.0^{\mathrm{a}}$ & 13.48 & & $62.8^{\mathrm{a}}$ & 15.61 & 0.9687 \\
L(w) (in) & $1.05^{\mathrm{a}}$ & 0.0135 & & $1.07^{\mathrm{b}}$ & 0.0259 & 0.0015 \\
SFC(w) \% & $9.97^{\mathrm{a}}$ & 0.9206 & & $8.43^{\mathrm{b}}$ & 1.5973 & 0.0033 \\
UQL(w) (in) & $1.30^{\mathrm{a}}$ & 0.0108 & & $1.32^{\mathrm{b}}$ & 0.0170 & 0.0145 \\
Fineness (millitex) & $168.9^{\mathrm{a}}$ & 3.5 & & $175.6^{\mathrm{b}}$ & 6.0 & 0.0010 \\
Mat & $0.93^{\mathrm{a}}$ & 0.0107 & & $0.96^{\mathrm{b}}$ & 0.0311 & 0.0008 \\
\hline
\end{tabular}

Note. * Means in rows with the same letter were not significantly different at 0.05 level $(\mathrm{n}=29)$.

\subsection{HVI Analysis}

HVI analysis results were given in Table 2. A one-way ANOVA test indicated the elongation (Elg) and trash count (TrCnt) differed significantly as a function of the lint cleaner $(\mathrm{p}<0.05)$. The other HVI properties were not significantly different between cleaners. The ABLC had higher trash count (22.6) than the STLC (20.7). this result was consistent to the AFIS analysis results. The mean of the micronaire, strength, and UI with both ABLC and STLC were almost the same. SFI were slightly improved with the ABLC, but not significantly. The reflectance $(\mathrm{Rd})$ and yellowness $(+\mathrm{b})$ were about the same with ABLC and STLC. In the report by Sui and Byler (2012), the ABLC significantly reduced SFI $(\mathrm{p}=0.0104)$, and the yellowness $(+\mathrm{b})$ with ABLC was significantly lower than STLC $(\mathrm{p}<0.0001)$.

Table 2. Effect of the lint cleaners on the selected HVI fiber quality

\begin{tabular}{|c|c|c|c|c|c|}
\hline \multirow{2}{*}{ HVI Fiber Property } & \multicolumn{2}{|c|}{ ABLC } & \multicolumn{2}{|c|}{ STLC } & \multirow{2}{*}{$\operatorname{Pr}>F$} \\
\hline & Mean* & Std & Mean & Std & \\
\hline Mic & $4.54^{\mathrm{a}}$ & 0.0839 & $4.53^{\mathrm{a}}$ & 0.0535 & 0.5908 \\
\hline UHML (in) & $1.24^{\mathrm{a}}$ & 0.0202 & $1.23^{\mathrm{a}}$ & 0.0199 & 0.1132 \\
\hline UI (\%) & $83.4^{\mathrm{a}}$ & 0.7028 & $83.5^{\mathrm{a}}$ & 0.6154 & 0.3056 \\
\hline SFI (\%) & $5.92^{\mathrm{a}}$ & 1.2146 & $6.21^{\mathrm{a}}$ & 1.2528 & 0.1487 \\
\hline Str (g/tex) & $32.8^{\mathrm{a}}$ & 1.0029 & $32.5^{\mathrm{a}}$ & 0.9833 & 0.1851 \\
\hline Elg $(\%)$ & $6.02^{\mathrm{a}}$ & 0.1701 & $5.94^{\mathrm{b}}$ & 0.1443 & 0.0048 \\
\hline $\mathrm{Rd}$ & $80.5^{\mathrm{a}}$ & 1.4636 & $80.8^{\mathrm{a}}$ & 0.7031 & 0.1935 \\
\hline$+\mathrm{b}$ & $7.85^{\mathrm{a}}$ & 0.1580 & $7.86^{\mathrm{a}}$ & 0.2107 & 0.8075 \\
\hline $\operatorname{TrCnt}$ & $22.6^{\mathrm{a}}$ & 5.0700 & $20.68^{b}$ & 4.3545 & 0.0148 \\
\hline $\operatorname{TrAr}(\%)$ & $0.31^{\mathrm{a}}$ & 0.1185 & $0.30^{\mathrm{a}}$ & 0.0668 & 0.5208 \\
\hline
\end{tabular}

Note. * Means in rows with the same letter were not significantly different at 0.05 level $(\mathrm{n}=149)$.

\subsection{Lint Waste}

Figure 3 showed the visual comparison of the lint wastes from ABLC and STLC. It is obversed that there was more trash and less lint content in the lint waste with ABLC (Figures 3 and 4). Lint waste rate (LWR) and the turnout were given in Table 3. The LWR with ABLC was significantly lower than that with STLC $(\mathrm{P}=0.0002)$. Mean of the LWR with ABLC was $2.1 \%$ while it was $3.3 \%$ with STLC. This indicated that $2.8 \mathrm{~kg}$ lint could be saved and added in each $225 \mathrm{~kg}$ bale of cotton by using ABLC, which is beneficial to cotton producers. The turnout rate didn't statistically differ between ABLC and STLC $(\mathrm{p}=0.7676)$ though it was slightly higher with ABLC (36.0\%) than with STCL (35.7\%). 


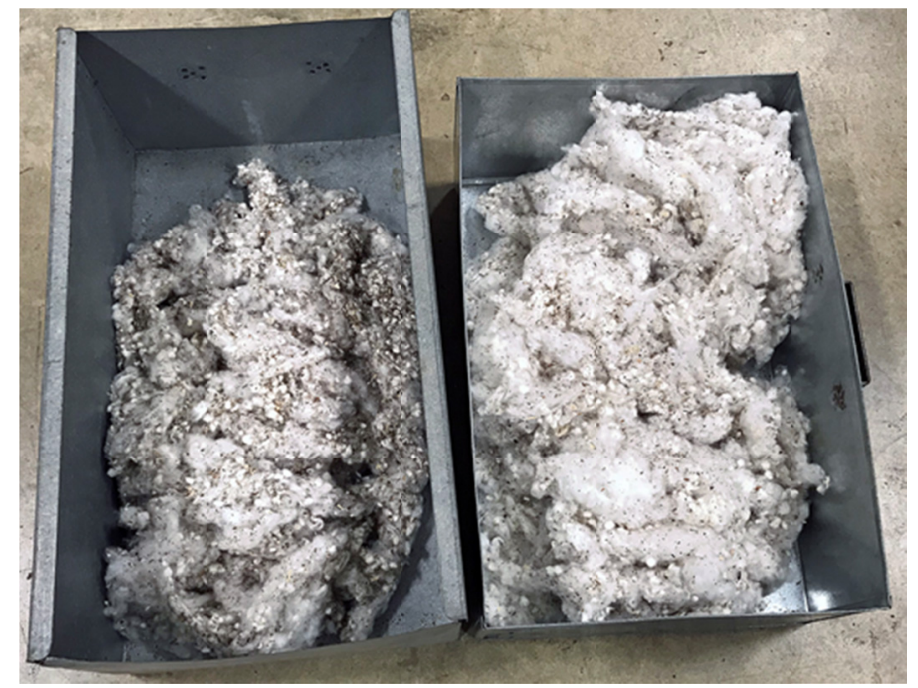

Figure 3. Lint waste from ABLC (left) and STLC (right)

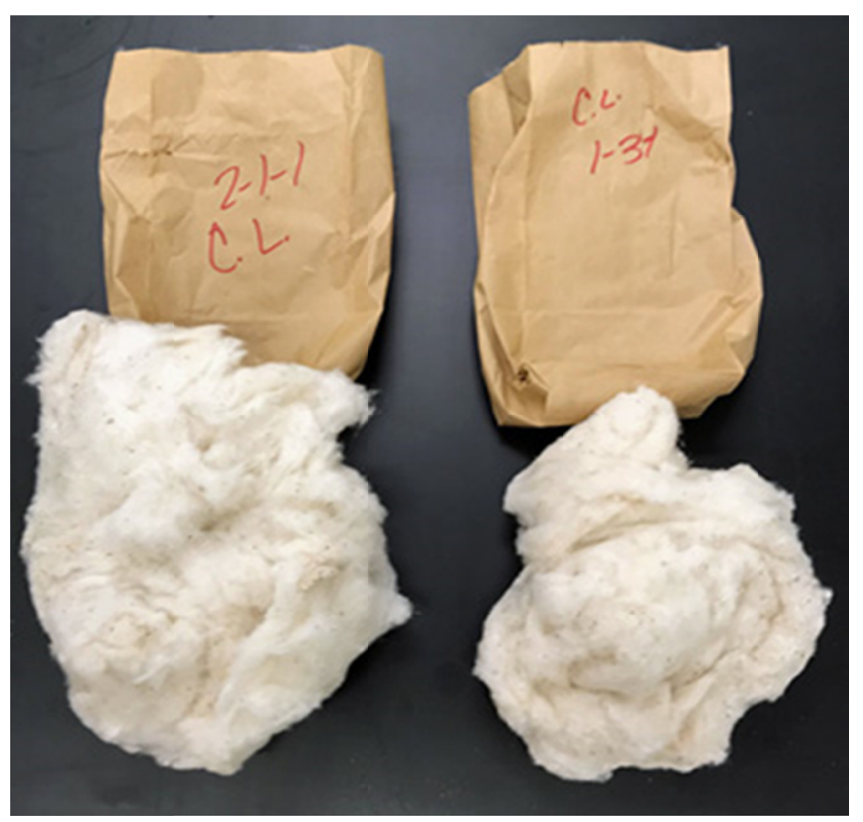

Figure 4. Showing the amount of lint from 75 grams lint waste generated by ABLC (right) and STLC (left)

Table 3. Results of lint waste rate and turnout rate with ABLC and STLC

\begin{tabular}{lllllll}
\hline \multirow{2}{*}{ Parameter } & \multicolumn{2}{c}{ ABLC } & & \multicolumn{2}{c}{ STLC } & \multirow{2}{*}{ Pr $>$ F } \\
\cline { 2 - 3 } \cline { 5 - 7 } & Mean* & Std & & Mean & Std & \\
\hline Lint Waste Rate (\%) & $2.09^{\mathrm{a}}$ & 0.1429 & & $3.32^{\mathrm{b}}$ & 0.0702 & 0.0002 \\
Turnout Rate (\%) & $36.0^{\mathrm{a}}$ & 1.73 & & $35.7^{\mathrm{a}}$ & 0.58 & 0.7676 \\
\hline
\end{tabular}

Note. ${ }^{*}$ Means in rows with the same letter were not significantly different at 0.05 level $(\mathrm{n}=6)$.

Shirley data (Table 4) showed that the effect of the lint cleaner on lint content in the lint waste was significant. In average, there was $44 \%$ less lint in the lint waste using ABLC than that using STLC, and that $39 \%$ of lint waste from ABLC was cleaned lint while $56 \%$ of the lint waste from STLC was cleaned lint. This result generally agreed with, but slightly higher than that reported by Sui and Byler (2012). Visible waste in the lint waste with ABLC was significantly different from that with STLC $(<.0001)$. In $75 \mathrm{~g}$ lint waste, ABLC had $44.5 \mathrm{~g}$ visible waste while STLC had $31.9 \mathrm{~g}$. 
Comparing the ABLC reported in this article to the one reported by Sui and Byler (2012), the ABLC reported by Sui and Byler (2012) performed better in preserving fiber quality and reducing amount of cleaned lint in the lint waste. This could be caused by the nozzle size of the air-bar and the air-pressure used in the tests. The nozzle size of the air-bar in the ABLC reported by Sui and Byler (2012) was larger than that used in this study. However, the air-pressure used in this study was $827.4 \mathrm{kPa}$ (120 psi) while it was $413.7 \mathrm{kPa}(60 \mathrm{psi})$ used by Sui and Byler (2012). Airflow force for lint cleaning was a function of the nozzle size and air-pressure. More research was necessary to find the optimal nozzle size and air-pressure for the lint cleaning process.

There was no difference in MC in the seed-cotton and the lint which were ginned by ABLC and STLC (Table 5). Mean of the seed-cotton MC was $8.5 \%$ and the lint MC was 5.6\%. This result indicated that the cotton MC would have no effect on the performance tests of ABLC and STLC.

Table 4. Shirley separation of lint waste with ABLC and STLC, showing the amount of cleaned lint and wastes in $75 \mathrm{~g}$ lint waste

\begin{tabular}{|c|c|c|c|c|c|c|}
\hline \multirow{2}{*}{ Parameter } & \multicolumn{2}{|c|}{ ABLC } & \multicolumn{2}{|c|}{ STLC } & \multirow{2}{*}{$\operatorname{Pr}>F$} & \multirow{2}{*}{ No. of Obs. } \\
\hline & Mean* & Std & Mean & Std & & \\
\hline Cleaned Lint (g) & $29.0^{\mathrm{a}}$ & 1.07 & $41.7^{\mathrm{b}}$ & 0.95 & $<.0001$ & 18 \\
\hline Visible Waste (g) & $44.5^{\mathrm{a}}$ & 1.06 & $31.9^{\mathrm{b}}$ & 1.09 & $<.0001$ & 18 \\
\hline Top Visible Waste Trays (g) & $0.0638^{\mathrm{a}}$ & 0.0192 & $0.0556^{\mathrm{a}}$ & 0.0159 & 0.3513 & 17 \\
\hline Bottom Visible Waste Trays (g) & $0.2075^{\mathrm{a}}$ & 0.0531 & $0.2155^{\mathrm{a}}$ & 0.0536 & 0.7605 & 17 \\
\hline
\end{tabular}

Note. * Means in rows with the same letter were not significantly different at 0.05 level.

Table 5. Results of moisture content measurement

\begin{tabular}{|c|c|c|c|c|c|}
\hline \multirow{2}{*}{ Parameter } & \multicolumn{2}{|c|}{ ABLC } & \multicolumn{2}{|c|}{ STLC } & \multirow{2}{*}{$\operatorname{Pr}>F$} \\
\hline & Mean* & Std & Mean & Std & \\
\hline Seed-Cotton Moisture (\%) & $8.50^{\mathrm{a}}$ & 0.62 & $8.58^{\mathrm{a}}$ & 0.77 & 0.8364 \\
\hline Lint moisture (\%) & $5.58^{\mathrm{a}}$ & 0.17 & $5.62^{\mathrm{a}}$ & 0.24 & 0.6955 \\
\hline
\end{tabular}

Note. $*$ Means in rows with the same letter were not significantly different at 0.05 level $(\mathrm{n}=18)$.

\section{Conclusion}

A new air-bar device was developed and implemented for an air-bar lint cleaner (ABLC) prototype. The ABLC was tested in comparison with a conventional saw-type lint cleaner (STLC). The ABLC was a new type of lint cleaner that used pressurized-air to assist in removing non-lint materials from lint cotton in ginning process. Preliminary tests of ABLC prototype were conducted. Results showed that ABLC generated less lint waste and had a higher turnout rate than STLC. Use of ABLC could save $2.8 \mathrm{~kg}$ of lint in each $225 \mathrm{~kg}$ bale of cotton. There was more lint in the lint waste from STLC than that from ABLC. This result was agreed with that reported by Sui and Byler (2012). In HVI analysis, results indicated the fiber properties in length, uniformity, short fiber content, and color were not significantly different between ABLC and STLC. However, the AFIS analysis showed that STLC had better performance than ABLC in fiber length and short fiber content while the trash and dust content with ABLC was lower than STLC. It was noted that some results in AFIS and HVI analysis were not consistent with that reported by Sui and Byler (2012). These could be due to the configuration change of the air-bar and the different air pressures used in the tests. The ABLC used in the test only replaced one grid bar with one air-bar. More than one air-bar could be used in one ABLC, and better performance could be expected with a multi-air-bar lint cleaner. The operating efficiency and effectiveness of ABLC could be affected by many factors including the nozzle size of the air-bar, air-pressure, direction of the airflow, distance between the air-bar nozzles and the saw cylinder. More research is necessary to further prove the concept of ABLC and improve its performance in preserving cotton fiber quality.

\section{Acknowledgements}

The author would like to thank the staff at USDA-ARS CGRU at Stoneville, Mississippi for their assistance in this study. 


\section{Disclaimer}

Mention of a commercial product is solely for the purpose of providing specific information and should not be construed as a product endorsement by the author or the institution with which the author is affiliated.

\section{References}

Anthony, W. S. (2000). Methods to reduce lint cleaner waste and damage. Trans. ASAE, 43(2), 221-229.

Anthony, W. S., \& Mayfield, W. D. (1994). Cotton Ginners Handbook. Agricultural Handbook 503 (pp. 102-104). U.S. Department of Agriculture, USA.

Anthony, W. S., \& McCaskill, O. L. (1972). Development of a model cotton ginning system. ASAE paper, presented at Southeastern Regional Meeting, St. Joseph, Mich.: ASAE.

Baker, R. V. (1987). Influence of Lint Cleaning on Fiber Quality. Proceedings Beltwide Cotton Conference (p. 535). Memphis, Tenn.: Nat. Cotton Council. Am.

Baker, R. V., Hughs, S. E., \& Mangialardi, G. J. (1992). Lint cleaning: Basic principles and new developments. Proc. Beltwide Cotton Conf. (pp. 538-542). Memphis, Tenn.: Nat. Cotton Council. Am.

Columbus, E. P. (1985). Effect of lint cleaner saw speed and tooth density on cotton quality. Transactions of the ASAE, 28(5), 1692-1696.

Funk, P. A., Armijo, C. B., Hanson, A. T., Samani, Z. A., Macias-Corral, M. A., Smith, G. B., \& Riordan J. T. (2005). Converting gin and dairy wastes to methane. Transactions of ASAE, 48(3), 1197-1201.

Gordon, S. G., \& Bagshaw, K. M. (2007). The effect of working elements in the fixed batt saw lint cleaner on ginned fiber properties. Proc. Beltwide Cotton Conf. (pp. 1977-1982). Memphis, Tenn.: Nat. Cotton Council. Am.

Hughs, S. E., Gillum, M. N., Lalor, W. F., \& Vandoorn, D. (1992). Coupled lint cleaning: Solution to minimizing fiber damage. Proc. Beltwide Cotton Conf. (pp. 20-21). Memphis, Tenn.: Nat. Cotton Council. Am.

Rutherford, R. D., Doorn, D. W. V., \& Cory, M. D. (1999). The Lummus Sentinel lint cleaner. Proc. Beltwide Cotton Conf. (Vol. 1, pp. 81-85). Memphis, Tenn.: Nat. Cotton Council. Am.

Sui, R., \& Byler, R. K. (2012). Air-bar cotton lint cleaner. Appl. Engr. Agric., 28(2), 173-177.

Thomasson, J. A., Sui, R., \& Popov, P. (2007). Modeling cotton fiber dynamics in a lint cleaner. Proc. Beltwide Cotton Conf. (pp. 967-973). Memphis, Tenn.: Nat. Cotton Council. Am.

Zellweger Uster, Inc. (1997). Introduction Manual, Advanced Fiber Information System. Knoxville, Tennessee.

\section{Copyrights}

Copyright for this article is retained by the author(s), with first publication rights granted to the journal.

This is an open-access article distributed under the terms and conditions of the Creative Commons Attribution license (http://creativecommons.org/licenses/by/4.0/). 